\title{
THE EFFECT OF PULMONARY VASCULAR PRESSURES ON THE MECHANICAL PROPERTIES OF THE LUNGS OF ANESTHETIZED DOGS ${ }^{1}$
}

\author{
By HANS G. BORST, ${ }^{2}$ ERIK BERGLUND, ${ }^{3}$ JAMES L. WHITTENBERGER, JERE \\ MEAD, MAURICE McGREGOR,4 AND CLARENCE COLLIER 5
}

(From the Department of Physiology, Harvard University School of Public Health, Boston, Mass.)

(Submitted for publication June 24, 1957; accepted August 8, 1957)

Since the experiments of von Basch (1) it has been recognized that pulmonary vascular congestion influences the mechanical behavior of the lungs. A number of studies in patients with chronic congestive failure have demonstrated marked changes in pulmonary elasticity (2-6). It has not been possible to determine in such patients the relative contributions of pulmonary edema, other parenchymal changes, and vascular congestion per se to the observed changes. Experiments with acute congestion in man or living animals (7-10) and isolated lungs (11) have yielded conflicting results.

The purpose of the present study was to examine in the living animal the effects of acute changes in pulmonary arterial and venous pressures and blood flow on the mechanical behavior of the lungs. The left atrial pressure and the pulmonary blood flow were varied independently. In one set of experiments, volume-pressure curves were obtained during stepwise inflation and deflation of the lung over a wide range of volume starting from the passively collapsed state. In another group, pulmonary compliance and flow-resistance were studied during continuous cycling of the lungs in the normal tidal range of lung volume.

\footnotetext{
1 Supported by grants from the National Heart Institute, National Institutes of Health, Bethesda, Maryland, and the Life Insurance Medical Research Fund, New York, New York.

2 Present address: Chirurgische Universitaets-Klinik, Marburg/Lahn, Germany.

8 Present address: Renstromska Hospital, Goteborg, Sweden.

4 Eli Lilly South African Fellow. Present address: McGill University, School of Medicine, Montreal, Quebec, Canada.

5 Fellow of the National Foundation for Infantile Paralysis. Present address: Department of Physiology, College of Medical Evangelists, Loma Linda, California.
}

METHOD
All experiments were done in open-chest dogs. The dogs, weighing 16 to $26 \mathrm{Kg}$., were anesthetized with Nembutal (25 to $45 \mathrm{mg}$. per $\mathrm{Kg}$. body weight, intravenously). The chest was opened by splitting the sternum, and the chest wall was retracted to minimize crowding of the intrathoracic viscera during inflation of the lungs. The right ventricle was replaced by a pump without interruption of the circulation as in an experimental preparation previously described (12). Systemic venous blood was diverted into a reservoir from which it was pumped into either the main pulmonary artery or into the two pulmonary artery branches separately.

When both pulmonary arteries were cannulated, the blood flow in the lung to be studied was varied by changing distribution of flow. In addition, pulmonary flow could be varied by changing pump output. Left atrial pressure was varied by mechanically altering the systemic arterial resistance (constriction of the ascending aorta, inflation of balloon in ascending aorta, systemic A-V shunt). Sometimes additional adjustment of left atrial pressure was obtained with an overflow system between the left atrium and the venous reservoir. In this way changes could be made in pulmonary flow or left atrial pressure independent of each other.

Pulmonary blood flows were measured with rotameters. Pressures in the pulmonary arteries distal to the respective cannulae, in the left atrium, and in the femoral or carotid arteries were measured with electromanometers. These values were recorded on a direct-writing Sanborn oscillograph.

Two methods were used to measure the mechanical characteristics of the lung.

1. Steprevise inflation and deflation of one lung (eight dogs). In this group of experiments, the blood flow to each lung was measured and could be varied independently. The trachea was divided by means of a G. Wright doublelumen cannula (13), which afforded air-tight separation of the two lungs. Airway pressures were recorded with an inductance manometer from points near the carina. The lung under study was connected to a closed system filled with a gas mixture which had approximately the same initial oxygen and carbon dioxide tensions as mixed venous blood; the gas exchange in this lung was thereby minimized. The other lung was ventilated with 30 per cent oxygen by a Starling pump. 
A hand-operated Starling pump was interposed between the test lung and a spirometer. The lung was allowed to deflate passively and was then inflated in steps (50 to $100 \mathrm{ml}$.) to an airway pressure of 30 to $40 \mathrm{~cm}$. $\mathrm{H}_{2} \mathrm{O}$ (see Figure 1). Deflation proceeded in similar steps; when a pressure near atmospheric was reached, the lungs were allowed to deflate passively into the spirometer. Transpulmonary pressure decreased in the intervals between successive volume steps during inflation; to a lesser extent, the reverse obtained during deflation. Because of this time dependence, it was necessary to follow a fixed time schedule for inflation and defiation. Each volume step had the same duration in each run. The interval between steps was varied in different experiments from 2 to 10 seconds. The interval between runs was one to five minutes, but constant during each experiment. The total time per run ranged from less than one minute to four minutes.

The volume returned to the spirometer on deflation was always less than the volume introduced on inflation. This deficit was greatest on the first cycle and appeared to result from air trapping within the lungs. After a few cycles the volume deficit reached a minimum value and remained constant ( 4 to 10 per cent of the inflation volume). This volume deficit was assumed to be due to a slight leakage.

During the inflation, the arterial pressure in the inflated lung rose due to the increased vascular resistance during inflation (Figure 1). In most of the experiments, the flow through that lung also decreased, in some runs up to 40 per cent; this could be avoided by adjusting screw clamps on the inflow tubings. In several experiments, the recorded left atrial pressure also increased slightly, probably due to elevation of the heart.

2. Continuous cycling of the lung volume over the normal tidal range (four dogs). In these experiments the main pulmonary artery was perfused and the airway was not divided. The animal was enclosed in a body plethysmograph. The tubes connecting the vascular system to the blood pump, and the trachea to the respiratory pump, ran through air-tight seals in the plethysmograph wall. The respiratory pump consisted of a blower with an electrically controlled valve, and was connected to the trachea. Versatile control of mean pressure, pressure amplitude, and cycling frequency was possible. The pressure pattern was approximately sinusoidal. End-expiratory carbon dioxide was continuously recorded with a Liston Becker carbon dioxide analyzer and maintained at desired level by adjustment of the tidal volume. No arterial hypoxia occurred. Lung volume changes were measured with an electrically recording Krogh spirometer connected to the body chamber. Transpulmonary pressure versus lung volume change and/or pressure versus flow rate were displayed on an oscilloscope.

Pulmonary compliance was measured as the ratio of the tidal volume to the change in transpulmonary pressure between the instants of zero air flow at the tidal volume extremes. Pulmonary flow-resistance, which includes air flow-resistance and tissue viscosity, was de-

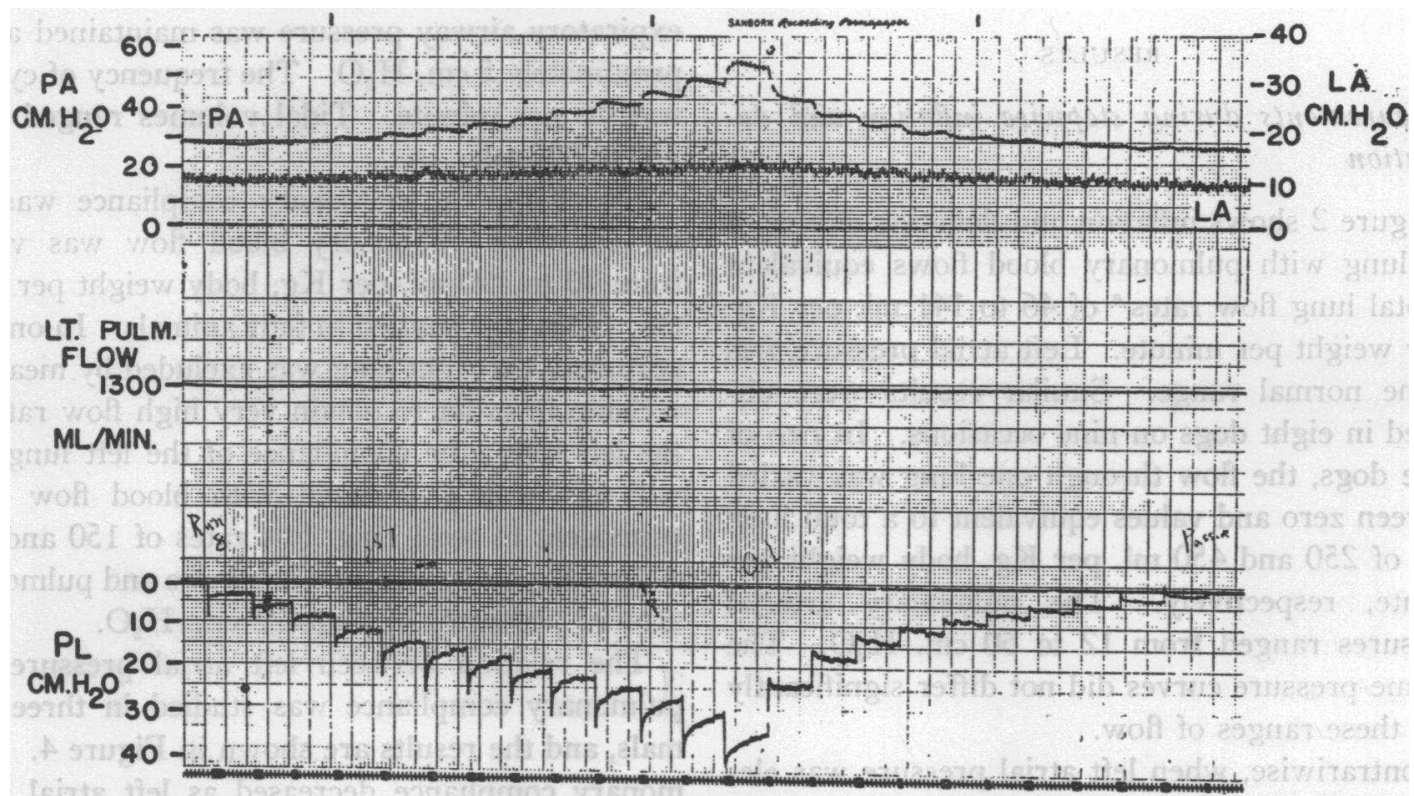

Fig. 1. Effects of Stepwise Inflation and Deflation of Left Lung on Vascular and Airway PresURES IN THE LUNG (EXPERIMENT No. 62)

PA refers to left pulmonary artery pressure; LA refers to left atrial pressure; $P_{L}$ refers to left airway pressure. Volume increments equal $95 \mathrm{ml}$. Each volume step was done in less than one-half second. There were 10 second intervals between each step. In this experiment, both pulmonary artery inflow tubings were constricted so that the changes in pulmonary vascular resistance did not alter flow significantly. 


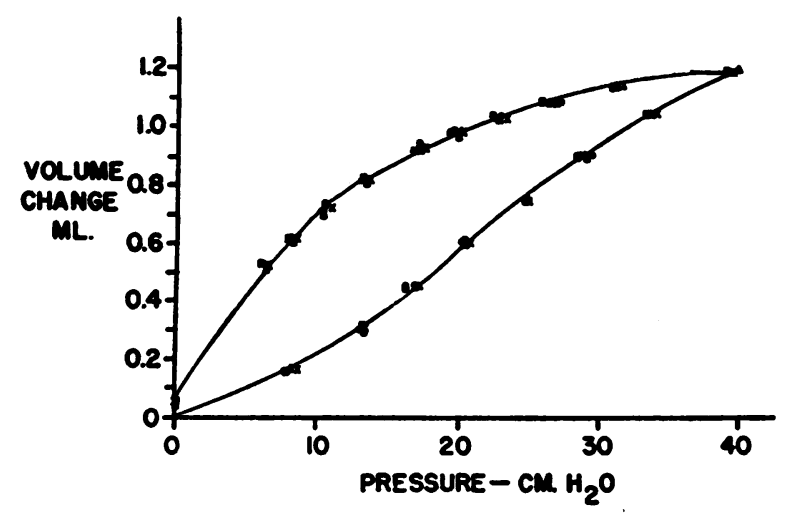

Fig. 2. Volume-Pressure Curves of the Right lung Obtained at Various Blood flows Through That Lung (Experiment No. 44)

Blood flows through that lung were equivalent to total pulmonary blood flows of $75(O), 46(\square), 141(X)$, and $61(\Delta) \mathrm{ml}$. per $\mathrm{Kg}$. body weight per minute. The corresponding pulmonary arterial pressures at the beginning of each run were $27,22,32$, and $27 \mathrm{~cm} . \mathrm{H}_{2} \mathrm{O}$. Lower limb obtained during inflation, upper during deflation. All pressures are final values during the intervals between volume steps.

termined by relating the resistive component of transpulmonary pressure fluctuations to simultaneous rates of air-flow (14).

\section{RESULTS}

Measurements during stepwise inflation and deflation

Figure 2 shows inflation and deflation curves of one lung with pulmonary blood flows equivalent to total lung flow rates ${ }^{6}$ of 46 to $141 \mathrm{ml}$. per $\mathrm{Kg}$. body weight per minute. Left atrial pressure was in the normal range. Similar results were obtained in eight dogs on nine occasions. In two of these dogs, the flow through one lung was varied between zero and values equivalent to a total lung flow of 250 and $450 \mathrm{ml}$. per $\mathrm{Kg}$. body weight per minute, respectively. The pulmonary arterial pressures ranged from 12 to $60 \mathrm{~cm} . \mathrm{H}_{2} \mathrm{O}$. The volume-pressure curves did not differ significantly over these ranges of flow.

Contrariwise, when left atrial pressure was elevated to $30 \mathrm{~cm} . \mathrm{H}_{2} \mathrm{O}$ or more, there was a small but definite change in the volume-pressure loops (Figure 3). At large volumes, both during inflation and deflation, the transpulmonary pressure

- Assuming a normal right/left flow ratio of $60 / 40$. was slightly higher. In two of these experiments and in a third (not illustrated), there was, however, no change when left atrial pressure was elevated to 15 to $25 \mathrm{~cm} . \mathrm{H}_{2} \mathrm{O}$. All changes were immediately reversible unless pulmonary edema developed. In one experiment, in which the left atrial pressure was repeatedly in excess of $40 \mathrm{~cm}$. $\mathrm{H}_{2} \mathrm{O}$ for more than 15 seconds, the changes were not reversible; at the termination of the experiment, frothy fluid was found in the lung.

In two experiments the following observation was made: With the lung passively collapsed at the conclusion of a run, a sudden lowering of left atrial pressure was accompanied by further emptying of the lung; e.g., a $225 \mathrm{ml}$. decrease in volume was recorded when the left atrial pressure was lowered from 55 to $15 \mathrm{~cm} . \mathrm{H}_{2} \mathrm{O}$. The change in lung volume was proportional to the change in left atrial pressure. No corresponding increases in lung volume were found when the left atrial pressure was suddenly raised to high levels.

\section{Measurements during continuous volume cycling}

In these experiments, the normal tidal range and frequency of breathing were simulated. The endexpiratory airway pressure was maintained at approximately $5 \mathrm{~cm} . \mathrm{H}_{2} \mathrm{O}$. The frequency of cycling was 16 per minute. Tidal volumes ranged from 130 to $300 \mathrm{ml}$.

No change in pulmonary compliance was observed when pulmonary blood flow was varied from 40 to $190 \mathrm{ml}$. per $\mathrm{Kg}$. body weight per minute. This was studied in four animals. In one experiment, the right lung was excluded by means of a clamp in order to obtain very high flow rates in the left lung; the compliance of the left lung was not significantly changed with blood flow rates equivalent to total lung flow rates of 150 and 370 $\mathrm{ml}$. per $\mathrm{Kg}$. body weight per minute and pulmonary arterial pressures of 20 to $75 \mathrm{~cm} . \mathrm{H}_{2} \mathrm{O}$.

The relation between left atrial pressure and pulmonary compliance was studied in three animals, and the results are shown in Figure 4. Pulmonary compliance decreased as left atrial pressure was increased. At left atrial pressures of 50 $\mathrm{cm} . \mathrm{H}_{2} \mathrm{O}$ the decrease in pulmonary compliance was 20 to 30 per cent. Pulmonary compliance returned to control levels simultaneously with reduction of left atrial pressure. 

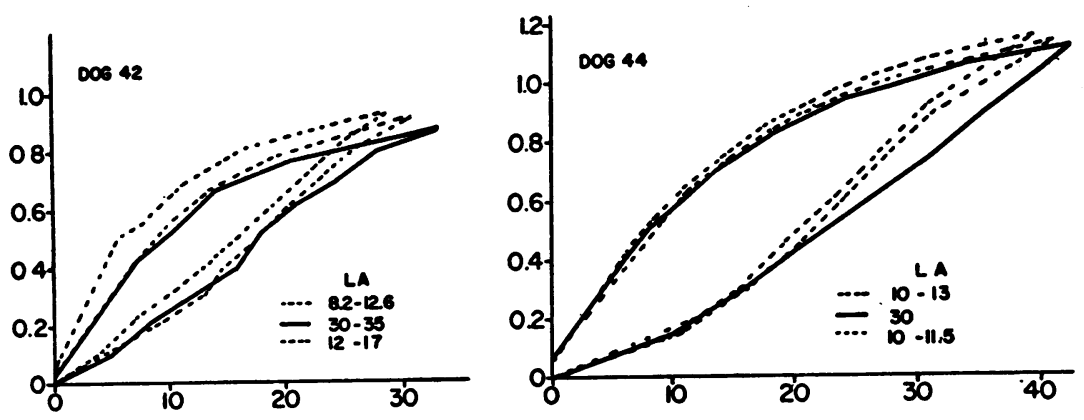

LITERS

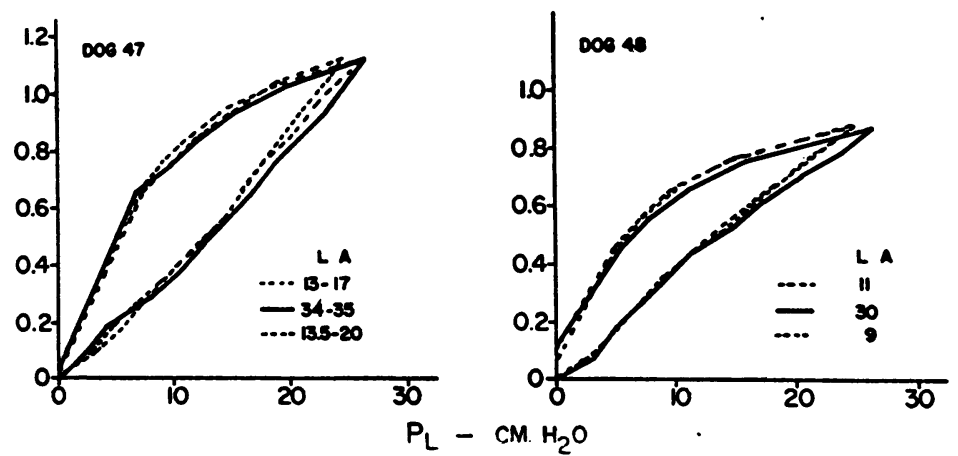

Fig. 3. Volume-Pressure Curves of One lung of Four Animals at Various Left Atrinl Pressures

Control curves (interrupted lines) were obtained before and after the curves at high atrial pressure (solid line).

In two experiments, the cycling rate of the respirator was increased from 16 to 120 c.p.m. Pulmonary compliance values were closely similar at the two frequencies (less than 10 per cent difference), both at low and high left atrial pressures.

As has been pointed out, compliance changes occurring with transient elevation of left atrial pressure were immediately reversible. In two experiments, pulmonary edema was intentionally produced by repeated short-term elevations of left atrial pressure. Pulmonary compliance decreased progressively from more than 0.035 to less than $0.005 \mathrm{~L}$. per $\mathrm{cm} . \mathrm{H}_{2} \mathrm{O}$ and remained low despite reduction of left atrial pressure to control levels.
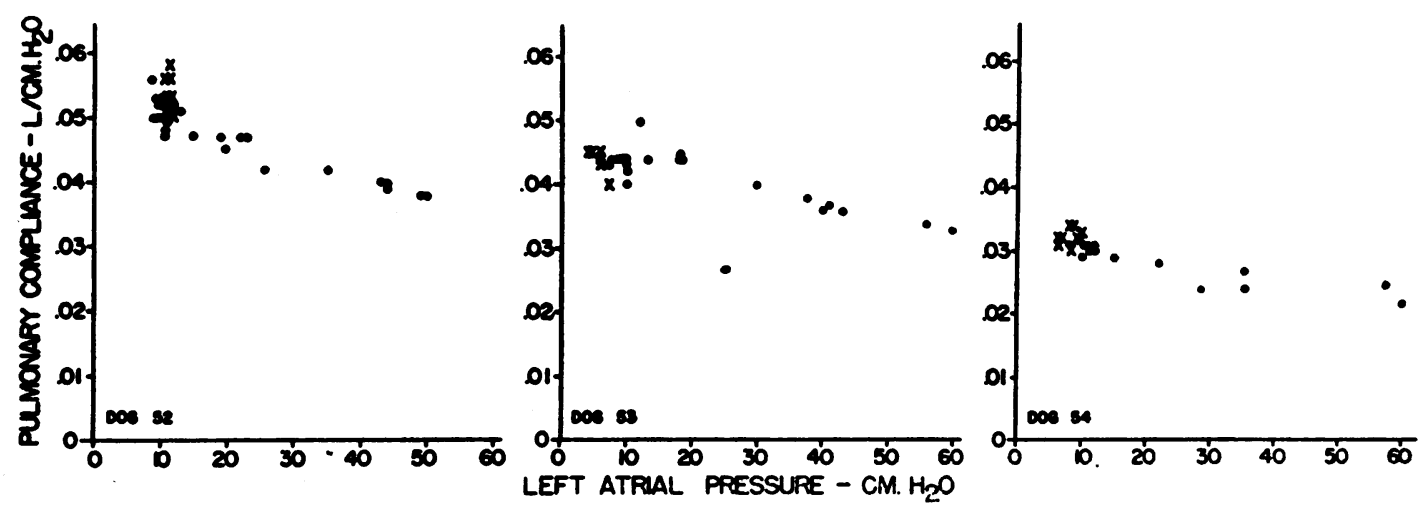

Fig. 4. Relation Between Left Atrial Pressure and Lung Compliance in Three Dogs

Values denoted by crosses were obtained first; then the left atrial pressures were varied repeatedly over the range of left atrial pressures. 

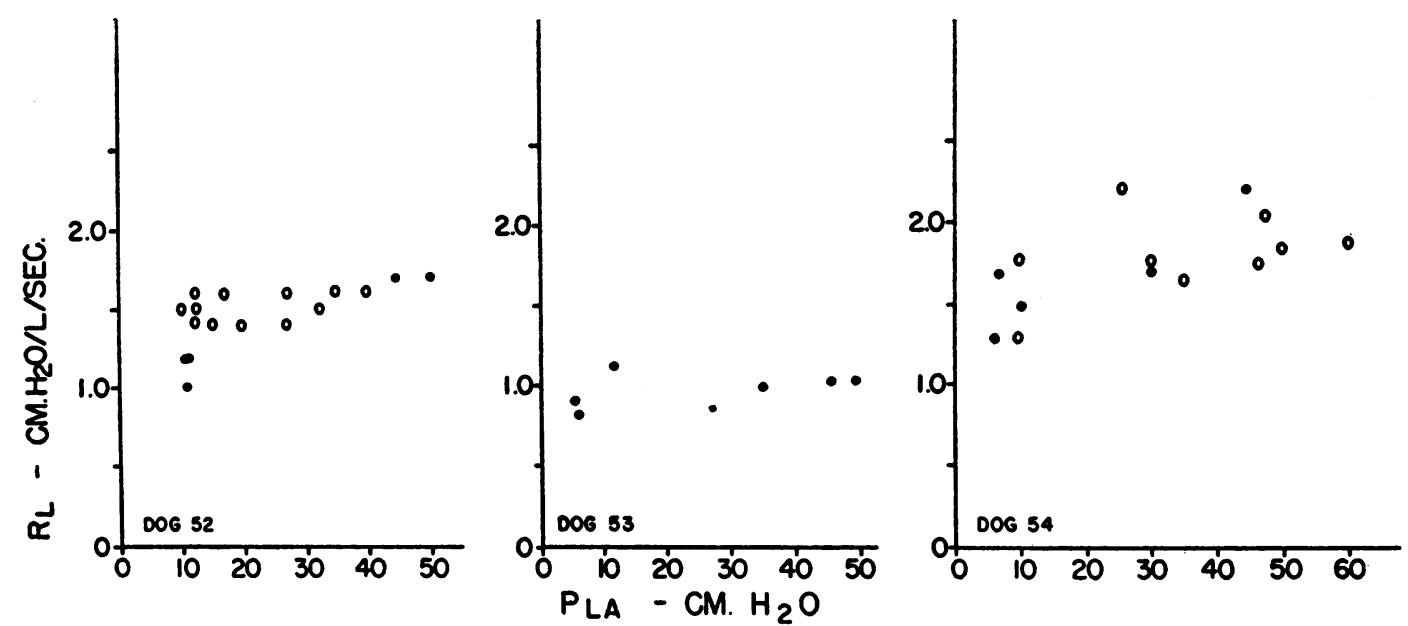

Fig. 5. Pulmonary Flow-Resistance at Various left Atrial Pressures in Three Dogs

The values denoted by dots and circles were obtained in two consecutive runs less than one hour apart.

The presence of edema was confirmed by the appearance of froth in the airway.

Pulmonary flow-resistance (air-flow resistance and tissue viscance) did not change over the range of pulmonary arterial pressures and blood flows studied. With rises in left atrial pressure, pulmonary flow-resistance was unchanged or showed a slight increase (Figure 5).

\section{DISCUSSION}

In 1887 , von Basch produced acute pulmonary vascular engorgement in living dogs and observed changes in the mechanical behavior of the lungs. In open-chest preparations, ventilation was produced by means of a pump with a fixed pressure amplitude. With congestion the tidal volume decreased, but at the same time the end-expiratory lung volume increased. Von Basch regarded the reduction in tidal excursion as evidence of increased lung stiffness (i.e., reduced compliance), and the increased end-expiratory volume as evidence of erectile behavior of lung capillaries.

More recent animal studies have in general confirmed von Basch's work, although the phenomenon of Lungenschwellung or "lung swelling" has not been further investigated. Drinker, Peabody, and Blumgart showed that occlusion of pulmonary veins of cats was associated with a reduction in pulmonary ventilation, and that these changes were immediately reversible (8). It is not possible, however, to conclude from their data whether these changes related to altered elastic behavior of the lungs or to changes in flow-resistance. Mack, Grossman, and Katz found decreases in lung distensibility following acute vascular engorgement in excised dog lungs and in lungs of living dogs (9). A limitation was that measurements were made over extremely limited ranges of lung volume increase $(25 \mathrm{ml}$. in excised lungs, $60 \mathrm{ml}$. in vivo), and were initiated from the passively collapsed state. Heyer, Holman, and Shires found marked reduction in lung distensibility following rapid infusion of saline solution (10). The lungs of these animals were found post mortem to be hemorrhagic and heavy, and it is not possible to dissociate from their results the possible contribution of pulmonary edema. None of the above studies included measurements of vascular pressures or rates of blood flow through the lungs.

The present study was stimulated by earlier findings in this laboratory that there was a moderate reduction in pulmonary compliance when left atrial pressure was raised to $70 \mathrm{~cm} . \mathrm{H}_{2} \mathrm{O}$ by clamping the aorta in the open-chest dog (15). No measurements of pulmonary blood flow were made. Later, Frank, Radford, and Whittenberger measured the effect of pulmonary vascular engorgement on the static pressure-volume curves of excised cat lungs (11). The lungs were filled with either fluid or air, starting from the air-free state. In the comparatively limited range of vascular pressures studied ( 0 to $16 \mathrm{~cm} . \mathrm{H}_{2} \mathrm{O}$ ), only minimal changes in the pressure-volume behavior were found.

In the present study, it was possible to examine separately in the living animal the mechanical ef- 
fects of changes in pulmonary blood flow and pulmonary arterial pressure from those of left atrial pressure variations. Furthermore, the lungs were studied over a wide range of volume changes as well as under conditions simulating normal breathing.

Large variations of pulmonary blood flow did not influence the mechanical behavior of the lungs. Elevation of left atrial pressure, on the other hand, was accompanied by definite but small changes. The compliance, obtained during continuous cycling, was reduced when the left atrial pressure was acutely elevated. This reduction was roughly proportional to the elevation of left atrial pressure, and compliance fell 20 to 30 per cent below control values. Results in agreement with these were later found in experiments in this laboratory on anesthetized closed-chest dogs (16). The volumepressure curve in the static runs was also slightly changed, but only when the left atrial pressure was elevated to values above $25 \mathrm{~cm} . \mathrm{H}_{2} \mathrm{O}$.

The fact that the compliance is influenced by the pulmonary venous pressure but not by the pulmonary arterial pressure suggests that the effect is due either to distension of the veins or capillaries or to increased filtration through the capillary walls. If the latter were the case, this would require an extremely rapid fluid exchange, inasmuch as the compliance returned to control level within 10 seconds after the left atrial pressure had been lowered from 50 to $6 \mathrm{~cm} . \mathrm{H}_{2} \mathrm{O}$.

The degree of reduction of pulmonary compliance with pulmonary venous engorgement observed is of a considerably smaller magnitude than that reported by Bondurant, Hickam, and Isley in normal human subjects following acute central congestion, produced either by inflation of an antigravity suit or submersion in water (7). In the present studies, pulmonary compliance decreased not more than 30 per cent when left atrial pressures were increased to $60 \mathrm{~cm} . \mathrm{H}_{2} \mathrm{O}$. Bondurant and associates reported compliance reduction of more than 50 per cent under conditions when left atrial pressure presumably was not greater than $45 \mathrm{~cm} . \mathrm{H}_{2} \mathrm{O}$. The discrepancy between these results may represent a true difference between the behavior of dog and human lungs. On the other hand, the reliability of esophageal pressure as a measure of intrapleural pressure in circumstances of central vascular congestion is not known.
The changes in compliance observed in these experiments are of small magnitude compared to those observed in patients with chronic congestive failure or pulmonary hypertension (2-6). If our findings can be applied to human lungs, it is likely that the changes observed in such patients are largely caused by factors other than the pulmonary congestion per se, such as effusion, other chronic changes in the parenchyma and vessel walls, or increased heart size.

The "asthma" attacks occurring in patients with hypertensive heart disease are supposedly accompanied by increased air-flow resistance. In our experiments, however, the flow-resistance of the lung was not altered significantly by large changes in pulmonary flow or left atrial pressure. This may indicate that the increased air-flow resistance in these patients is not directly caused by the pulmonary congestion.

\section{SUMMARY}

Blood flow to one or both lungs and the left atrial pressure were varied independently. The mechanical properties of the lungs were studied. This was done during stepwise excursions of the lung between passive collapse and a large volume, and during rapid cycling in the normal tidal range of lung volume.

Changes of pulmonary blood flow between 0 and $450 \mathrm{ml}$. per $\mathrm{Kg}$. body weight per minute, and pulmonary arterial pressures between 12 and $60 \mathrm{~cm}$. $\mathrm{H}_{2} \mathrm{O}$, with the left atrial pressure maintained almost constant, did not significantly alter the mechanical behavior of the lung.

Elevation of left atrial pressure to between 30 and $40 \mathrm{~cm} \cdot \mathrm{H}_{2} \mathrm{O}$ was accompanied by a small change of the volume-pressure curve of the lung. Compliance, observed during cycling in the tidal volume range, decreased only 20 to 30 per cent at left atrial pressures of 50 to $60 \mathrm{~cm} . \mathrm{H}_{2} \mathrm{O}$. These changes were reversible, except when pulmonary edema occurred.

The relation of the observed data to clinical findings is discussed.

\section{REFERENCES}

1. von Basch, S., Ueber eine Funktion des Capillardruckes in den Lungenalveolen. Wiener Med. Blatter, 1887, 15, 465. 
2. Christie, R. V., and Meakins, J. C., The intrapleural pressure in congestive heart failure and its clinical significance. J. Clin. Invest., 1934, 13, 323.

3. Marshall, R., McIlroy, M. B., and Christie, R. V., The work of breathing in mitral stenosis. Clin. Sc., 1954, 13, 137.

4. Brown, C. C., Jr., Fry, D. L., and Ebert, R. V., The mechanics of pulmonary ventilation in patients with heart disease. Am. J. Med., 1954, 17, 438.

5. Saxton, G. A., Jr., Rabinowitz, M., Dexter, L., and Haynes, F., The relationship of pulmonary compliance to pulmonary vascular pressures in patients with heart disease. J. Clin. Invest., 1956, 35, 611.

6. Frank, N. R., Lyons, H. A., Siebens, A. A., and Nealon, T. F., Pulmonary compliance in patients with cardiac disease. Am. J. Med., 1957, 22, 516.

7. Bondurant, S., Hickam, J. B., and Isley, J. K., Pulmonary and circulatory effects of acute pulmonary vascular engorgement in normal subjects. J. Clin. Invest., 1957, 36, 59.

8. Drinker, C. K., Peabody, F. W., and Blumgart, H. L., The effect of pulmonary congestion on the ventilation of the lungs. J. Exper. Med., 1922, 35, 77.

9. Mack, I., Grossman, M., and Katz, L. N., The effect of pulmonary vascular congestion on the distensibility of the lungs. Am. J. Physiol., 1947, $150,654$.

10. Heyer, H. E., Holman, J., and Shires, G. T., The diminished efficiency and altered dynamics of respiration in experimental pulmonary congestion. Am. Heart J., 1948, 35, 463.

11. Frank, N. R., Radford, E. P., Jr., and Whittenberger; J. L., Interrelationships between pulmonary vascular distention and elastic behavior of excised cat lungs, In preparation.

12. Borst, H. G., McGregor, M., Whittenberger, J. L., and Berglund, E., Influence of pulmonary arterial and left atrial pressures on pulmonary vascular resistance. Circ. Research, 1956, 4, 393.

13. Rahn, H., and Bahnson, H. T., Effect of unilateral hypoxia on gas exchange and calculated pulmonary blood flow in each lung. J. Applied Physiol., 1953, 6, 105.

14. Mead, J., and Whittenberger, J. L., Physical properties of human lungs measured during spontaneous respiration. J. Applied Physiol., 1953, 5, 779.

15. Whittenberger, J. L., Mead, J., Affeldt, J., and Berglund, E., Unpublished observations, 1952.

16. Cook, C. D., Mead, J., and Schreiner, G. L., Pulmonary mechanics during induced pulmonary edema in anesthetized dogs, In preparation. 